\title{
EGFR, SMAD7, and TGFBR2 Polymorphisms Are Associated with Colorectal Cancer in Patients with Lynch Syndrome
}

\author{
ABRAM BUNYA KAMIZA ${ }^{1}$, WEN-CHANG WANG ${ }^{2}$, JENG-FU YOU ${ }^{3,4}$, REIPING TANG $^{3,4}$, \\ YEN-TING WANG ${ }^{1}$, HUEI-TZU CHIEN ${ }^{5}$, CHIH-HSIUNG LAI ${ }^{5}$, LI-LING CHIU ${ }^{5,6}$, \\ TSAI-PING LO ${ }^{7}$, KUAN-YI HUNG ${ }^{7}$, CHAO AGNES HSIUNG ${ }^{7}$ and CHIH-CHING YEH ${ }^{1,8}$ \\ ${ }^{1}$ School of Public Health, College of Public Health, Taipei Medical University, Taipei, Taiwan, R.O.C.; \\ ${ }^{2}$ The Ph.D. Program for Translational Medicine, College of Medical Science and Technology, \\ Taipei Medical University, Taipei, Taiwan, R.O.C.; \\ ${ }^{3}$ Colorectal Section, Department of Surgery, Chang Gung Memorial Hospital, Taoyuan, Taiwan, R.O.C.; \\ ${ }^{4}$ School of Medicine, Chang Gung University, Taoyuan, Taiwan, R.O.C.; \\ ${ }^{5}$ Department of Public Health, College of Medicine, Chang Gung University, Taoyuan, Taiwan, R.O.C.; \\ ${ }^{6}$ Department of Nutrition and Health Sciences, \\ Chang Gung University of Science and Technology, Taoyuan, Taiwan, R.O.C.; \\ ${ }^{7}$ Institute of Population Health Sciences, National Health Research Institutes, Miaoli, Taiwan, R.O.C.; \\ ${ }^{8}$ Department of Public Health, China Medical University, Taichung, Taiwan, R.O.C.
}

\begin{abstract}
Background/Aim: Epidermal growth factor receptor (EGFR), mothers against decapentaplegic homolog 7 (SMAD7) and transforming growth factor betta (TGFB) are crucial for colorectal cancer (CRC) tumorigenesis. This study investigated whether polymorphisms in EGFR, SMAD7, and $T G F B$ are associated with CRC risk in patients with Lynch syndrome. Materials and Methods: Genotyping was performed using Sequenom iPLEX MassArray. Association between genetic polymorphisms and CRC was assessed using a weighted Cox proportional hazard model. Results: Patients carrying the AA genotype of EGFR rs2227983 had a significantly higher CRC risk than those carrying the $G$ allele $(H R=2.55,95 \% C I=1.25-5.17)$. The dominant model of SMAD7 rs12953717 (CT + TT genotypes) significantly increased CRC risk (HR=2.17, 95\% CI=1.12-4.16) when compared to the wild-type CC genotype. Similarly, the GG genotype of TGFBR2 rs6785358 significantly increased the risk of CRC (HR=21.1, 95\% CI=5.06-88.1) compared to the
\end{abstract}

Correspondence to: Chih-Ching Yeh, Ph.D., School of Public Health, College of Public Health, Taipei Medical University, 250 Wu-Hsing Street, Taipei Taiwan, R.O.C. Tel: +886227361661 ext. 6534, Fax: +886 227384831, e-mail: ccyeh@tmu.edu.tw; Chao Agnes Hsiung, $\mathrm{PhD}$, Institute of Population Health Sciences, National Health Research Institutes, Miaoli 350, Taiwan, R.O.C. Tel: +886 37246166 ext. 36100, Fax: +886 37586467, e-mail: hsiung@nhri.org.tw

Key Words: EGFR, SMAD7, TGFB, polymorphisms, colorectal cancer, CRC risk, Lynch syndrome.
AA genotype. Conclusion: EGFR, SMAD7, and TGFBR2 are associated with CRC risk in patients with Lynch syndrome.

Lynch syndrome is a cancer predisposition disorder caused by a germline mutation in one of the mismatch repair (MMR) genes (1). MMR genes encode proteins that prevent both mutation and cancer development (2). Loss of function in MMR proteins usually results in error-prone DNA replication and microsatellite instability (MSI) (3). Approximately 1 in 3,140 individuals harbors a germline mutation in $M L H 1$ or $M S H 2$ and are at a higher risk of colorectal cancer (CRC) and other cancers than the general population $(4,5)$. Moreover, these patients exhibit an earlier onset of CRC and other cancers compared to the general population $(6,7)$.

Lichtenstein et al. estimated that $35 \%$ of inherited genetic factors are associated with CRC susceptibility (8). One of these genetic factors is the transforming growth factor beta $(T G F B)$, whose mutations have been identified in colorectal tumors with MSI (9), a feature of Lynch syndrome. The TGFB signaling pathway is mediated via the TGFB receptor (TGFBR) or mothers against decapentaplegic homolog 7 (SMAD7) (9). Epidermal growth factor receptor (EGFR) inhibits $T G F B$ signaling pathway through SMAD7 (10). Studies have reported that single nucleotide polymorphisms (SNPs) in EGFR, SMAD7, and TGFB are associated with cancer predisposition (11-13). More specifically, EGFR is involved in angiogenesis, metastasis, tumor invasion, and survival; TGFB plays a crucial role in cell proliferation, differentiation, and apoptosis, whereas SMAD7 is an 
inhibitor of TGFB and other SMAD family members (1416). Prior studies have indicated that TGFBR2 rs 3087465 , $E G F R$ rs2227983, and SMAD7 rs12953717 SNPs are associated with CRC risk (17-20). By contrast, other studies have found non-significant associations between EGFR rs2227983, SMAD7 rs2337104, and SMAD7 rs12953717 SNPs and CRC (21-23).

$\mathrm{CRC}$ is a heterogeneous disease caused by numerous biological interactions of different signaling pathways. Therefore, as part of an initiative to identify genetic factors associated with CRC susceptibility in patients with Lynch syndrome, this study investigated whether EGFR rs2227983, SMAD7 (rs12953717 and rs2337104), TGFB1 (rs1800468 and rs1800489), TGFBR1 rs334354, and TGFBR2 (rs3087465 and rs6785358) SNPs are associated with CRC susceptibility in patients with Lynch syndrome in Taiwan.

\section{Materials and Methods}

Study population. Using the Amsterdam II criteria, patients suspected of harboring a germline mutation in MMR genes were recruited from seven hospitals located throughout Taiwan. These patients were enrolled into the Amsterdam criteria family registry as described by our previous studies (24-26). A total of 1,014 probands and their relatives were recruited from 135 hereditary nonpolyposis colorectal cancer (HNPCC) families (patients that meet the Amsterdam criteria, but are not genetically tested for germline mutations). The protocol of this study was approved by the Taipei Medical University Institutional Review Board and also the Taiwan National Health Research Institute.

Informed consent was obtained from all patients and genetic analyses were performed in all patients who met the Amsterdam criteria. Of the 1014 HNPCC patients who met the Amsterdam II criteria, 303 were identified as harboring $M L H 1$ or $M S H 2$ germline mutation; the details of these are available in our previous studies $(25,26)$. Forty-one of these 303 patients were excluded because their SNPs results were unavailable. We also excluded two patients who harbored mutations in both $M L H 1$ and $M S H 2$. Eventually, 260 patients with germline mutations were recruited from 62 Lynch syndrome families.

Data collection. Clinical data from all patients were collected by nurses using a structured questionnaire, which included sociodemographic factors, medical, and family histories of cancer, as described by our previous studies $(25,26)$. Patients with Lynch syndrome were biennially followed-up for their recent cancer diagnoses. CRC and other cancer diagnoses were confirmed by cancer registry reports, pathology reports, medical reports, and death certificates.

Genotyping analyses. Sequenom iPLEX MassArray (Sequenom, San Diego, CA, USA) was used to genotype EGFR, $S M A D 7$, and $T G F B$ as described by our prior studies $(25,26)$. DNA sample of $10 \mathrm{ng}$ was added to a polymerase chain reaction (PCR) mix containing Qiagen HotStarTaq (Qiagen, Valencia, CA, USA). PCR was performed according to Sequenom protocols and primers used in this study were obtained from Integrated DNA Technologies (Coralville, IA, USA). Assays were designed by MassARRAY
Assay Design, Version 3.1. For quality control, $10 \%$ of randomly selected samples were repeated yielding a reproducibility of $100 \%$.

Statistical analysis. Frequency distribution of all genotypes was examined for conformance to the Hardy-Weinberg equilibrium (HWE). Chi-squared goodness-of-fit test with one degree freedom was used to compare the differences between the observed and expected genotype frequencies of all the SNPs. Time at risk was considered to begin at birth and end at cancer diagnoses, death, or loss to follow-up. Patients who did not receive a diagnosis of CRC were censored at the date of their last known contact or in February 2012.

Since germline mutation carriers were recruited using nonprobability sampling methods, to minimize for this nonrandom ascertainment, probability sampling weights were calculated and applied to each germline mutation carrier as previously described (27). Hazard ratios (HRs) and 95\% confidence intervals (CIs) for the association between EGFR, SMAD7, and TGFB SNPs and CRC development were calculated in three genetic models (codominant, dominant, and recessive) using a weighted Cox proportional hazard model. The multivariable hazard model was used to adjust for the potential confounding factors including sex, MMR genes, year of birth, and regular colonoscopy. Furthermore, we adjusted for family and cluster correlations of these patients by using a robust sandwich covariance model, as described by a previous study (28).

For haplotype analysis, PHASE version 2.1 was used to construct haplotypes from genotypes of SMAD7 and TGFBR2 SNPs as described by Stephens et al. (29). PHASE is a Bayesian method for haplotyping population genotype data. The most frequent haplotype was used for comparison with other haplotypes. All tests were 2 -sided and statistical significance was set at $<0.05$. All data analyses were performed by using SAS Version 9.4 for Windows.

\section{Results}

Genotype frequency distributions of EGFR, SMAD7, and $T G F B$ SNPs are presented in Table I. All the SNPs, with the exception of TGFBI rs 1800468 , conformed to HWE genotypic proportions. Because TGFB1 rs1800468 violated HWE, it was excluded from further analysis. Approximately $46.2 \%$ of participants harbored the heterozygous GA genotype of EFGR rs2227983. Moreover, 51.5\% and 94.2\% of participants harbored the wild-type homozygous genotypes of SMAD7 rs 12953717 and rs2337104, respectively. Similarly, $51.8 \%$ and $49.8 \%$ of participants harbored the heterozygous genotypes of TGFB1 rs 1800469 and TGFBR1 rs334354, respectively. More than $70 \%$ of germline mutation carriers in this study harbored the wild-type alleles of TGFBR2 rs3087465 and rs6785358.

The associations of EGFR, SMAD7, and TGFB SNPs with CRC risk are presented in Table II. After adjustment for potential confounding factors, hazard ratio (HR) showed that the variant homozygous AA genotype of EGFR rs2227983 was significantly associated with an increased risk of CRC in the recessive model compared with the wild-type $\mathrm{G}$ allele $(\mathrm{HR}=2.55,95 \% \mathrm{CI}=1.25-5.17)$. The codominant $(\mathrm{HR}=2.30$, 95\% $\mathrm{CI}=1.15-4.58)$ and dominant $(\mathrm{HR}=2.17,95 \% \mathrm{CI}=1.12$ 4.16) models of the SMAD7 rs12953717 SNP were 
Table I. Frequency distributions of EGFR, SMAD7, and TGFB polymorphisms in patients with Lynch syndrome.

\begin{tabular}{|c|c|c|c|c|c|c|c|c|}
\hline Gene & SNP & $\begin{array}{l}\text { Wild allele } \\
(\%)\end{array}$ & $\begin{array}{c}\text { Heterozygous } \\
(\%)\end{array}$ & $\begin{array}{c}\text { Variant allele } \\
(\%)\end{array}$ & Nucleotide & MAF & HWE & MAF CHB ${ }^{\dagger}$ \\
\hline$E G F R$ & rs2227983 & GG (23.4) & GA (46.2) & AA (30.4) & c. $1562 \mathrm{G}>\mathrm{A}$ & $A=0.5346$ & 0.242 & $\mathrm{~A}=0.4612$ \\
\hline SMAD7 & rs12953717 & CC (51.5) & СТ (40.8) & TT (7.7) & g. $48927559 \mathrm{C}>\mathrm{T}$ & $\mathrm{T}=0.2807$ & 0.878 & $\mathrm{~T}=0.2331$ \\
\hline SMAD7 & rs2337104 & TT (94.2) & $\mathrm{TC}(5.4)$ & $\mathrm{CC}(0.4)$ & g. $48936582 T>C$ & $\mathrm{C}=0.0557$ & 0.116 & $\mathrm{C}=0.0341$ \\
\hline$T G F B 1$ & rs 1800468 & $\mathrm{CC}(64.2)$ & CT (35.8) & TT (0) & c. $.3480 \mathrm{C}>\mathrm{T}$ & $\mathrm{T}=0.1788$ & 0.001 & $\mathrm{~T}=0.0049$ \\
\hline$T G F B 1$ & rs 1800469 & $\mathrm{CC}(22.3)$ & CT (51.8) & TT (25.9) & c. $29 \mathrm{C}>\mathrm{T}$ & $\mathrm{T}=0.5176$ & 0.559 & $\mathrm{~T}=0.4419$ \\
\hline$T G F B R 1$ & rs334354 & GG (29.7) & GA (49.8) & AA (20.5) & c. $1255+24 \mathrm{G}>\mathrm{A}$ & $A=0.4536$ & 0.938 & $\mathrm{~A}=0.4612$ \\
\hline$T G F B R 2$ & rs 3087465 & GG (70.4) & GA (26.1) & $\mathrm{AA}(3.5)$ & c. $-1216 A>G$ & $A=0.1653$ & 0.369 & $\mathrm{~A}=0.1748$ \\
\hline$T G F B R 2$ & rs6785358 & AA (79.2) & AG (18.9) & GG (1.9) & c. $3779 \mathrm{~A}>\mathrm{G}$ & $\mathrm{G}=0.1135$ & 0.308 & $\mathrm{G}=0.1553$ \\
\hline
\end{tabular}

$E G F R$, Epidermal growth factor receptor; SMAD7, mothers against decapentaplegic homolog 7; TGFB, transforming growth factor beta; SNP, single nucleotide polymorphism; MAF, minor allele frequency; CHB, Han Chinese in Beijing; HWE, Hardy-Weinberg equilibrium. ${ }^{\dagger}$ Allele frequency from other studies in Han Chinese population. Statistically significant results are shown in bold.

significantly associated with an increased risk of CRC. In addition, the variant homozygous CC genotype of SMAD7 rs2337104 was significantly associated with CRC risk $(\mathrm{HR}=5.21,95 \% \mathrm{CI}=2.31-11.7)$ compared with the wild-type T allele. Similarly, the variant homozygous GG genotype of TGFBR2 rs6785358 was significantly associated with an increased risk of CRC compared with the homozygous wildtype A allele $(\mathrm{HR}=21.1,95 \% \mathrm{CI}=5.06-88.1)$.

Furthermore, the association between the haplotypes of SMAD7 and TGFBR2 SNPs and CRC risk was assessed in germline mutation carriers (Table III). Linkage disequilibrium of rs3087465 and rs6785358 was D' $=0.62$ for TGFBR2. However, rs12953717 and rs2337104 were in linkage equilibrium for $S M A D 7$. The TT haplotype of SMAD7 SNPs was significantly associated with CRC risk $(\mathrm{HR}=2.18,95 \% \mathrm{CI}=1.13-4.19)$ compared to the most frequent CT haplotype. However, haplotypes of TGFBR2 were not associated with CRC risk. Table IV presents the combined effect of risk genotypes of EGFR rs2227983, SMAD7 rs12953717, and TGFBR2 rs6785358 on CRC risk, in patients with Lynch syndrome. Patients who harbored at least one risk genotype had higher $\mathrm{CRC}$ risk $(\mathrm{HR}=2.94,95 \%$ $\mathrm{CI}=1.39-6.21$ for patients with one risk genotype; $\mathrm{HR}=4.89$, $95 \% \mathrm{CI}=2.10-11.3$ for patients with two risk genotypes) than those without risk genotypes.

\section{Discussion}

The present study revealed that EGFR rs2227983, SMAD7 rs 12953717, and TGFBR2 rs6785358 SNPs are associated with CRC susceptibility in germline mutation carriers. Haplotype analysis revealed that the TT haplotype of $S M A D 7$ SNPs was associated with an increased CRC risk compared to the most frequent CT haplotype. Moreover, the presence of at least one risk genotype significantly increased CRC risk.
EGFR plays a crucial role in cell adhesion, proliferation, differentiation, and migration (14). In this study, harboring variant AA genotype of rs2227983 significantly increased CRC risk. Our findings are consistent with Lurje et al. (30) who reported that patients with AA genotype of rs2227983, also termed rs11543848, were associated with poor CRC outcome and shorter progression-free survival than other genotypes. In contrast, another study reported that the wildtype GG genotype of rs2227983 is associated with CRC risk (31). Moreover, patients carrying wild-type genotype have been reported to have a poorer prognosis than those carrying the variant genotype $(18,32)$. The rs2227983 polymorphism, an arginine-to-lysine amino acid substitution at codon 521 of the EGFR, has been shown to decrease ligand binding affinity, thus attenuating growth stimulation, tyrosine kinase activation and the induction of proto-oncogenes (33). The increased risk of CRC in patients carrying variant genotype of rs2227983 in this study is a novel finding. The mechanism for this observed association is currently unclear. However, it has been indicated that EGFR inhibits TGFB signaling pathway through SMAD7 signaling pathways (10). Disruption of TGFB signaling pathways by SMAD7 leads to various forms of tumorigenesis (34), thus increasing cancer risk. Moreover, other polymorphisms of the EGFR, including rs712829 and rs712830, have also been reported to be associated with CRC susceptibility (32).

In this study, patients with variant T allele of SMAD7 rs12953717 were associated with an increased risk of CRC, corroborating previous studies $(20,35-38)$. In addition, a meta-analysis reported that SMAD7 rs12953717 was associated with CRC risk (19). In contrast, a cohort study reported a non-significant association between SMAD7 rs12953717 and CRC in germline mutation carriers (39). The non-significant results reported by Wijnen et al. may have been due to a lack of statistical power. SMAD7 encodes an inhibitory protein that acts as an antagonist of TGFB by 
Table II. EGFR, SMAD7, and TGFB polymorphisms and risk of CRC in patients with Lynch syndrome.

\begin{tabular}{|c|c|c|c|c|c|c|c|}
\hline Polymorphism & $\begin{array}{l}\text { Total } \\
\text { cohort }\end{array}$ & $\begin{array}{l}\text { Person- } \\
\text { years }\end{array}$ & $\begin{array}{l}\text { CRC } \\
\text { cases }\end{array}$ & $\begin{array}{c}\text { Crude } \\
\text { HR }(95 \% \mathrm{CI})\end{array}$ & $p$-Value & $\begin{array}{c}\text { Adjusted } \\
\operatorname{HR}(95 \% \mathrm{CI})^{\mathrm{a}}\end{array}$ & $p$-Value \\
\hline \multicolumn{8}{|c|}{$E G F R$ rs2227983 } \\
\hline \multicolumn{8}{|c|}{ Codominant model } \\
\hline GG & 61 & 2633 & 32 & 1.00 & & 1.00 & \\
\hline GA & 120 & 4973 & 53 & $0.60(0.30-1.17)$ & 0.135 & $0.49(0.21-1.12)$ & 0.093 \\
\hline AA & 79 & 3197 & 35 & $1.79(0.94-3.40)$ & 0.074 & $1.71(0.89-3.27)$ & 0.102 \\
\hline \multicolumn{8}{|c|}{ Dominant model } \\
\hline GG & 61 & 2633 & 32 & 1.00 & & 1.00 & \\
\hline $\mathrm{GA}+\mathrm{AA}$ & 199 & 8170 & 88 & $0.92(0.52-1.59)$ & 0.754 & $0.96(0.53-1.73)$ & 0.892 \\
\hline \multicolumn{8}{|c|}{ Recessive model } \\
\hline $\mathrm{GG}+\mathrm{GA}$ & 181 & 7606 & 85 & 1.00 & & 1.00 & \\
\hline AA & 79 & 3197 & 35 & $2.51(1.26-5.00)$ & 0.008 & $2.55(1.25-5.17)$ & 0.009 \\
\hline \multicolumn{8}{|c|}{ SMAD7 rs12953717 } \\
\hline \multicolumn{8}{|c|}{ Codominant model } \\
\hline $\mathrm{CC}$ & 134 & 5662 & 67 & 1.00 & & 1.00 & \\
\hline $\mathrm{CT}$ & 106 & 4365 & 46 & $2.17(1.14-4.11)$ & 0.017 & $2.30(1.15-4.58)$ & 0.018 \\
\hline TT & 20 & 775 & 7 & $1.50(0.51-4.40)$ & 0.457 & $1.43(0.44-4.58)$ & 0.544 \\
\hline \multicolumn{8}{|c|}{ Dominant model } \\
\hline $\mathrm{CC}$ & 134 & 5662 & 67 & 1.00 & & 1.00 & \\
\hline $\mathrm{CT}+\mathrm{TT}$ & 126 & 5140 & 53 & $2.06(1.13-3.73)$ & 0.017 & $2.17(1.12-4.16)$ & 0.021 \\
\hline \multicolumn{8}{|c|}{ Recessive model } \\
\hline $\mathrm{CC}+\mathrm{CT}$ & 240 & 10027 & 113 & 1.00 & & 1.00 & \\
\hline TT & 20 & 775 & 7 & $1.08(0.37-3.14)$ & 0.891 & $0.92(0.28-2.93)$ & 0.885 \\
\hline \multicolumn{8}{|c|}{$S M A D 7$ rs2337104 } \\
\hline \multicolumn{8}{|c|}{ Codominant model } \\
\hline $\mathrm{TT}$ & 245 & 10174 & 109 & 1.00 & & 1.00 & \\
\hline $\mathrm{TC}$ & 14 & 589 & 10 & $1.02(0.36-2.88)$ & 0.975 & $1.30(0.48-3.51)$ & 0.605 \\
\hline $\mathrm{CC}$ & 1 & 39 & 1 & $6.07(3.15-11.6)$ & 0.001 & $5.21(2.31-11.7)$ & 0.001 \\
\hline \multicolumn{8}{|c|}{ Dominant model } \\
\hline $\mathrm{TT}$ & 245 & 10174 & 109 & 1.00 & & 1.00 & \\
\hline $\mathrm{TC}+\mathrm{CC}$ & 15 & 628 & 11 & $1.07(0.38-2.93)$ & 0.903 & $1.35(0.51-3.56)$ & 0.541 \\
\hline \multicolumn{8}{|c|}{ Recessive model } \\
\hline $\mathrm{TT}+\mathrm{TC}$ & 259 & 10763 & 119 & 1.00 & & 1.00 & \\
\hline $\mathrm{CC}$ & 1 & 39 & 1 & $6.06(3.19-11.5)$ & 0.001 & $5.11(2.29-11.3)$ & 0.001 \\
\hline \multicolumn{8}{|c|}{$T G F B 1$ rs $1800469^{\mathrm{b}}$} \\
\hline \multicolumn{8}{|c|}{ Codominant model } \\
\hline $\mathrm{CC}$ & 57 & 2349 & 25 & 1.00 & & 1.00 & \\
\hline $\mathrm{CT}$ & 132 & 5526 & 62 & $1.14(0.64-2.00)$ & 0.651 & $1.15(0.59-2.20)$ & 0.675 \\
\hline TT & 66 & 2674 & 29 & $1.45(0.79-2.65)$ & 0.229 & $1.33(0.68-2.56)$ & 0.401 \\
\hline \multicolumn{8}{|c|}{ Dominant model } \\
\hline $\mathrm{CC}$ & 57 & 2349 & 25 & 1.00 & & 1.00 & \\
\hline $\mathrm{CT}+\mathrm{TT}$ & 198 & 8200 & 91 & $1.31(0.73-2.35)$ & 0.357 & $1.29(0.66-2.51)$ & 0.454 \\
\hline \multicolumn{8}{|c|}{ Recessive model } \\
\hline $\mathrm{CC}+\mathrm{CT}$ & 189 & 7875 & 87 & 1.00 & & 1.00 & \\
\hline TT & 66 & 2674 & 29 & $1.32(0.71-2.47)$ & 0.375 & $1.20(0.64-2.22)$ & 0.559 \\
\hline \multicolumn{8}{|c|}{$T G F B R 1 \mathrm{rs} 334354^{\mathrm{c}}$} \\
\hline Codominant $\mathrm{r}$ & & & & & & & \\
\hline GG & 77 & 3197 & 39 & 1.00 & & 1.00 & \\
\hline GA & 129 & 5318 & 60 & $0.90(0.45-1.75)$ & 0.752 & $0.92(0.44-1.91)$ & 0.819 \\
\hline AA & 53 & 2249 & 20 & $0.93(0.38-2.23)$ & 0.874 & $1.10(0.44-2.70)$ & 0.832 \\
\hline Dominant mo & & & & & & & \\
\hline GG & 77 & 3197 & 39 & 1.00 & & 1.00 & \\
\hline $\mathrm{GA}+\mathrm{AA}$ & 182 & 7567 & 80 & $0.91(0.47-1.77)$ & 0.785 & $0.96(0.46-1.98)$ & 0.921 \\
\hline Recessive mo & & & & & & & \\
\hline $\mathrm{GG}+\mathrm{GA}$ & 206 & 8515 & 99 & 1.00 & & 1.00 & \\
\hline AA & 53 & 2249 & 20 & $1.00(0.48-2.06)$ & 0.999 & $1.17(0.61-2.22)$ & 0.628 \\
\hline
\end{tabular}


Table II. Continued

\begin{tabular}{|c|c|c|c|c|c|c|c|}
\hline Polymorphism & $\begin{array}{l}\text { Total } \\
\text { cohort }\end{array}$ & $\begin{array}{l}\text { Person- } \\
\text { years }\end{array}$ & $\begin{array}{l}\text { CRC } \\
\text { cases }\end{array}$ & $\begin{array}{c}\text { Crude } \\
\text { HR }(95 \% \text { CI })\end{array}$ & $p$-Value & $\begin{array}{c}\text { Adjusted } \\
\operatorname{HR}(95 \% \mathrm{CI})^{\mathrm{a}}\end{array}$ & $p$-Value \\
\hline \multicolumn{8}{|c|}{$T G F B R 2$ rs3087465 } \\
\hline \multicolumn{8}{|c|}{ Codominant model } \\
\hline GG & 183 & 7591 & 77 & 1.00 & & 1.00 & \\
\hline AG & 68 & 2805 & 37 & $0.71(0.34-1.43)$ & 0.333 & $0.62(0.29-1.30)$ & 0.204 \\
\hline AA & 9 & 406 & 6 & $1.63(0.35-7.46)$ & 0.529 & $2.41(0.52-11.1)$ & 0.258 \\
\hline \multicolumn{8}{|c|}{ Dominant model } \\
\hline GG & 183 & 7591 & 77 & 1.00 & & 1.00 & \\
\hline $\mathrm{AG}+\mathrm{AA}$ & 77 & 3211 & 43 & $0.75(0.37-1.48)$ & 0.406 & $0.67(0.32-1.38)$ & 0.281 \\
\hline \multicolumn{8}{|c|}{ Recessive model } \\
\hline $\mathrm{GG}+\mathrm{AG}$ & 251 & 10802 & 114 & 1.00 & & 1.00 & \\
\hline AA & 9 & 406 & 6 & $1.78(0.39-8.02)$ & 0.453 & $2.69(0.60-11.9)$ & 0.193 \\
\hline \multicolumn{8}{|c|}{$T G F B R 2$ rs6785358 } \\
\hline \multicolumn{8}{|c|}{ Codominant model } \\
\hline AA & 206 & 8442 & 90 & 1.00 & & 1.00 & \\
\hline GA & 49 & 2215 & 28 & $1.31(0.69-2.46)$ & 0.404 & $1.21(0.63-2.32)$ & 0.565 \\
\hline GG & 5 & 145 & 2 & $24.4(6.38-93.5)$ & 0.001 & $21.1(5.06-88.1)$ & 0.001 \\
\hline \multicolumn{8}{|c|}{ Dominant model } \\
\hline AA & 206 & 8442 & 90 & 1.00 & & 1.00 & \\
\hline $\mathrm{GA}+\mathrm{GG}$ & 54 & 2360 & 30 & $1.34(0.71-2.52)$ & 0.359 & $1.25(0.65-2.40)$ & 0.499 \\
\hline \multicolumn{8}{|c|}{ Recessive model } \\
\hline $\mathrm{AA}+\mathrm{GA}$ & 255 & 10657 & 118 & 1.00 & & 1.00 & \\
\hline GG & 5 & 145 & 2 & $23.4(6.10-89.6)$ & 0.001 & $20.4(4.76-87.2)$ & 0.001 \\
\hline
\end{tabular}

$E G F R$, Epidermal growth factor receptor; SMAD7, mothers against decapentaplegic homolog 7; TGFB, transforming growth factor beta; CRC, colorectal cancer. aAdjusted for sex, colonoscopy, date of birth, familial clustering, and mutated MMR gene. bFive patients had missing genotype data. ${ }^{c}$ One patient had missing genotype data. Statistically significant results are shown in bold.

blocking phosphorylation of receptor-activated SMAD (40). Inhibition of TGFB results in blocking activation of downstream signaling pathways (16), which eventually lead to CRC carcinogenesis. Moreover, Broderick et al. showed that lower median SMAD7 mRNA expression was associated with $\mathrm{CRC}$ risk among patients harboring the variant $\mathrm{T}$ allele (35), which support our findings.

To date, only one study has investigated the association between SMAD7 rs2337104 and CRC (23). Akbari et al. reported that the TC genotype and $\mathrm{C}$ allele were associated with CRC risk (23), which are consistent with our findings. However, their results were not statistically significant. The rs2337104 is a T $>$ C polymorphism occurring at intron 3 of $S M A D 7$. The biological mechanism underlying the increased $\mathrm{CRC}$ risk among the variant $\mathrm{C}$ allele remains unclear, as it has rarely been investigated. Due to the low frequency of the minor $\mathrm{C}$ allele, our results should be interpreted with caution. Nevertheless, a haplotype analysis was performed and data revealed that the TT haplotype of rs12953717 and rs2337104 SNPs in SMAD7 was associated with an increased CRC risk. This finding confirms that the $\mathrm{T}$ allele of SMAD7 rs12953717 is a high-risk allele associated with CRC susceptibility.
To our best knowledge, this is the first study to report an association between TGFBR2 rs6785358 and CRC. The variant GG of rs6785358 was observed to be associated with CRC risk, compared to the A allele. Our findings are consistent with other studies $(41,42)$; however, these studies were conducted in patients with congenital heart defects and not in patients with CRC. Li et al. suggested that the polymorphisms of rs6785358 result in the decreased transcriptional activity of $T G F B R 2$ and its low protein expression (42), thus altering the signal transduction pathways, which may explain the increased risk of CRC among individuals harboring the variant $\mathrm{G}$ allele.

Since CRC is caused by numerous biological interactions of different signaling pathways, we evaluated the joint effect of harboring risk genotype on CRC risk. Our results revealed that carrying at least one risk genotype in EGFR rs2227983, SMAD7 rs12953717, and TGFBR2 rs6785358 significantly increased $\mathrm{CRC}$ risk. In addition to the significance of individual SNPs, genetic combination of relevant SNPs may contribute to CRC susceptibility, as demonstrated in this retrospective cohort study.

However, this study was limited by the inability to test other MMR genes including MSH6, PMS2, and EPCAM. 
Table III. Haplotypes of SMAD7 and TGFBR2 and CRC risk in patients with Lynch syndrome.

\begin{tabular}{|c|c|c|c|c|c|}
\hline Haplotypes & $\begin{array}{l}\text { Allele } \\
\text { n (\%) }\end{array}$ & $\begin{array}{c}\text { Crude } \\
\text { HR }(95 \% \mathrm{CI})\end{array}$ & $p$-Value & $\begin{array}{c}\text { Adjusted } \\
\text { HR }(95 \% \text { CI })^{\mathrm{a}}\end{array}$ & $p$-Value \\
\hline \multicolumn{6}{|l|}{$S M A D 7^{\mathrm{b}}$} \\
\hline $\mathrm{C} / \mathrm{T}$ & $358(69.3)$ & 1.00 & & 1.00 & \\
\hline $\mathrm{T} / \mathrm{T}$ & $146(27.8)$ & $2.07(1.13-3.76)$ & 0.017 & $2.18(1.13-4.19)$ & 0.019 \\
\hline $\mathrm{C} / \mathrm{C}$ & $16(2.9)$ & $1.25(0.41-3.70)$ & 0.694 & $1.65(0.54-4.85)$ & 0.384 \\
\hline $\mathrm{T} / \mathrm{C}$ & $0(0)$ & - & - & - & - \\
\hline \multicolumn{6}{|l|}{$T G F B R 2^{\mathrm{c}}$} \\
\hline $\mathrm{G} / \mathrm{A}$ & 387 (73.6) & 1.00 & & 1.00 & \\
\hline $\mathrm{A} / \mathrm{G}$ & $60(10.7)$ & $1.13(0.56-2.25)$ & 0.731 & $0.94(0.38-2.26)$ & 0.884 \\
\hline $\mathrm{A} / \mathrm{A}$ & $50(10.4)$ & $0.63(0.28-1.41)$ & 0.267 & $0.55(0.24-1.26)$ & 0.159 \\
\hline $\mathrm{G} / \mathrm{G}$ & $23(5.3)$ & $0.61(0.22-1.59)$ & 0.311 & $0.49(0.18-1.34)$ & 0.168 \\
\hline
\end{tabular}

SMAD7, Mothers against decapentaplegic homolog 7; TGFBR2, transforming growth factor beta receptor type 2; CRC, colorectal cancer. ${ }^{\text {Ad Adjusted }}$ for sex, colonoscopy, date of birth, familial clustering, and a mutated MMR gene. ${ }^{b}$ Haplotypes of rs 12953717 and rs $2337104 .{ }^{c}$ Haplotypes of rs3087465 and rs6785358. Statistically significant results are shown in bold.

Table IV. Combined effect of EGFR rs2227983, SMAD7 rs12953717, and TGFBR2 rs6785358 polymorphisms and risk of CRC in patients with Lynch syndrome.

\begin{tabular}{|c|c|c|c|c|c|c|c|}
\hline Risk genotype $^{\mathrm{a}}$ & $\begin{array}{l}\text { Total } \\
\text { cohort }\end{array}$ & $\begin{array}{c}\text { Person- } \\
\text { years }\end{array}$ & $\begin{array}{l}\text { CRC } \\
\text { cases }\end{array}$ & $\begin{array}{c}\text { Crude } \\
\text { HR }(95 \% \mathrm{CI})\end{array}$ & $p$-Value & $\begin{array}{c}\text { Adjusted } \\
\text { HR }(95 \% \text { CI })^{b}\end{array}$ & $p$-Value \\
\hline 0 & 92 & 3986 & 48 & 1.00 & & 1.00 & \\
\hline 1 & 127 & 5185 & 54 & $2.49(1.21-5.07)$ & 0.012 & $2.94(1.39-6.21)$ & 0.004 \\
\hline 2 & 40 & 1597 & 18 & $4.34(1.88-9.97)$ & 0.001 & $4.89(2.10-11.3)$ & 0.001 \\
\hline
\end{tabular}

$E G F R$, Epidermal growth factor receptor; $S M A D 7$, mothers against decapentaplegic homolog $7 ; T G F B R 2$, transforming growth factor beta receptor type 2; CRC, colorectal cancer. aRisk genotypes included EGFR rs2227983 AA, SMAD7 rs12953717 CT+TT, and TGFBR2 rs6785358 GG genotypes. bAdjusted for sex, colonoscopy, date of birth, familial clustering, and a mutated MMR gene. Statistically significant results are shown in bold.

Some patients were not willing to be followed-up; hence, some cancer cases were not recorded. In addition, the associations of EGFR, SMAD7, and TGFB SNPs with CRC could not be compared in patients without Lynch syndrome. The main strengths of this study are that all patients included were confirmed to have germline mutation in $M L H 1$ or $M S H 2$. Statistical methods that correctly adjust for ascertainment bias were used; thus, our results are comparable to others. Moreover, all cancer diagnoses were confirmed histologically.

In conclusion, EGFR rs2227983, SMAD7 rs12953717, and TGFBR2 rs6785358 SNPs are associated with CRC risk in Chinese patients with Lynch syndrome. Moreover, harboring at least one risk genotype of EGFR rs2227983, SMAD7 rs 12953717, and TGFBR2 rs6785358 significantly increases the risk of CRC in patients with Lynch syndrome.

\section{Acknowledgements}

The Authors would like to thank all patients and their families for participating in this study, as well as the staff of Chang Gung University and Chang Gung Memorial Hospital. This study was funded by the National Science Council, Executive Yuan, Taiwan (NSC 101-2314-B-038-057), Ministry of Science and Technology, Taiwan (MOST 104-2314-B-038-009), and WanFang Hospital, ChiMei Medical Center, and Hualien Tzu-Chi Hospital Joing Cancer Center Grant-Focus on Colon Cancer Research (Health and welfare surcharge of tobacco products: MOHW107-TDU-B-212-114020).

\section{References}

1 Lynch H, Lynch P, Lanspa S, Snyder C, Lynch J and Boland C: Review of the Lynch syndrome: history, molecular genetics, screening, differential diagnosis, and medicolegal ramifications. Clin Genet 76: 1-18, 2009. 
2 Li GM: Mechanisms and functions of DNA mismatch repair Cell Res 18: 85-98, 2008.

3 Funkhouser WK, Lubin IM, Monzon FA, Zehnbauer BA, Evans JP, Ogino S and Nowak JA: Relevance, pathogenesis, and testing algorithm for mismatch repair-defective colorectal carcinomas: a report of the association for molecular pathology. J Mol Diagn 14: 91-103, 2012.

4 Dunlop MG, Farrington SM, Nicholl I, Aaltonen L, Petersen G, Porteous $\mathrm{M}$ and Carothers A: Population carrier frequency of hMSH2 and hMLH1 mutations. Br J Cancer 83: 1643-1645, 2000 .

5 Watson P, Vasen HFA, Mecklin JP, Bernstein I, Aarnio M, Järvinen HJ, Myrhøj T, Sunde L, Wijnen JT and Lynch HT: The risk of extra-colonic, extra-endometrial cancer in the Lynch syndrome. Int J Cancer 123: 444-449, 2008.

6 Stigliano V, Sanchez-Mete L, Martayan A and Anti M: Earlyonset colorectal cancer: A sporadic or inherited disease? World J Gastroenterol 20: 12420-12430, 2014.

7 Fu L, Sheng JQ, Li XO, Jin P, Mu H, Han M, Huang JS, Sun ZQ, Li AQ, Wu ZT and Li SR: Mismatch repair gene mutation analysis and colonoscopy surveillance in Chinese Lynch syndrome families. Cell Oncol 36: 225-231, 2013.

8 Lichtenstein P, Holm NV, Verkasalo PK, Iliadou A, Kaprio J, Koskenvuo M, Pukkala E, Skytthe A and Hemminki K: Environmental and heritable factors in the causation of canceranalyses of cohorts of twins from Sweden, Denmark and Finland. N Engl J Med 343: 78-85, 2000.

9 Takayama T, Miyanishi K, Hayashi T, Sato Y and Niitsu Y: Colorectal cancer: genetics of development and metastasis. J Gastroenterol 41: 185-192, 2006.

$10 \mathrm{Xu} \mathrm{Y}$ and Pasche B: TGF-beta signaling alterations and susceptibility to colorectal cancer. Hum Mol Genet 16: 14-20, 2007.

11 Luwor RB, Baradaran B, Taylor LE, Iaria J, Nheu TV, Amiry N, Hovens CM, Wang B, Kaye AH and Zhu HJ: Targeting Stat 3 and Smad7 to restore TGF- $\beta$ cytostatic regulation of tumor cells in vitro and in vivo. Oncogene 32: 2433-2441, 2013.

12 Yang L, Wang YJ, Zheng LY, Jia YM, Chen YL, Chen L, Liu DG, Li XH, Guo HY, Sun YL, Tian XX and Fang WG: Genetic polymorphisms of TGFB1, TGFBR1, SNAI1 and TWIST1 are associated with endometrial cancer susceptibility in Chinese Han women. PLoS ONE 11: e0155270, 2016.

13 Liu X, Shan Y and Xue B: Int7G24A polymorphism (rs334354) and cancer risk. Arch Med Sci 9: 3-7, 2013.

14 Leite MS, Giacomin LC, Piranda DN, Festa-Vasconcellos JS, Indio-do-Brasil V, Koifman S, de Moura-Neto RS, de Carvalho MA and Vianna-Jorge R: Epidermal growth factor receptor gene polymorphisms are associated with prognostic features of breast cancer. BMC Cancer 14: 190, 2014.

15 Laskin JJ and Sandler AB: Epidermal growth factor receptor: a promising target in solid tumours. Cancer Treat Rev 30: 1-17, 2004.

16 Monteleone G, Boirivant M, Pallone F and MacDonald TT: TGF-beta1 and Smad7 in the regulation of IBD. Mucosal Immunol 1: S50-53, 2008.

17 Heldin $\mathrm{CH}$, Miyazono K and ten Dijke P: TGF-beta signalling from cell membrane to nucleus through SMAD proteins. Nature 390: 465-471, 1997.

18 Huang YS, Zhong Y, Yu L and Wang L: Association between the TGFBR2 G-875A polymorphism and cancer risk: evidence from a meta-analysis. Asian Pac J Cancer Prev 15: 8705-8708, 2014.
19 Wang WS, Chen PM, Chiou TJ, Liu JH, Lin JK, Lin TC, Wang HS and Su Y: Epidermal growth factor receptor R497K polymorphism is a favorable prognostic factor for patients with colorectal carcinoma. Clin Cancer Res 13: 3597-3604, 2007.

20 Huang $\mathrm{Y}, \mathrm{Wu} \mathrm{W}, \mathrm{Nie} \mathrm{M}, \mathrm{Li} \mathrm{C}$ and Wang L: SMAD7 polymorphisms and colorectal cancer risk: a meta-analysis of case-control studies. Oncotarget 7: 75561-75570, 2016.

21 Damavand B, Derakhshani S, Saeedi N, Mohebbi SR, Milanizadeh S, Azimzadeh P, Aghdaie HA and Zali MR: Intronic polymorphisms of the SMAD7 gene in association with colorectal cancer. Asian Pac J Cancer Prev 16: 41-44, 2015.

22 Wang Y, Zha L, Liao D and Li X: A Meta-Analysis on the Relations between EGFR R521K polymorphism and risk of cancer. Int J Genomics Proteomics 2014: e312102, 2014.

23 Torabizadeh Z, Nosrati A and Tahvildari S: Human epidermal growth factor receptor expression in colorectal cancer and its relationship with clinicopathological characteristics. Middle East J Dig Dis 8: 24-30, 2016.

24 Akbari Z, Safari-Alighiarloo N, Taleghani MY, Mirfakhar FS, Asadzadeh Aghdaei H, Vahedi M, Irani Shemirani A, Nazemalhosseini-Mojarad E and Zali MR: Polymorphism of SMAD7 gene (rs2337104) and risk of colorectal cancer in an Iranian population: a case-control study. Gastroenterol Hepatol Bed Bench 7: 198-205, 2014.

25 Tang R, Hsiung C, Wang JY, Lai CH, Chien HT, Chiu LL, Liu CT, Chen HH, Wang HM, Chen SX and Hsieh LL: Germ line MLH1 and MSH2 mutations in Taiwanese Lynch syndrome families: characterization of a founder genomic mutation in the MLH1 gene. Clin Genet 75: 334-345, 2009.

26 Kamiza AB, Hsieh LL, Tang R, Chien HT, Lai CH, Chiu LL, Lo TP, Hung KY, Wang CY, You JF, Hsiung CA and Yeh CC: Risk factors associated with colorectal cancer in a subset of patients with mutations in MLH1 and MSH2 in Taiwan fulfilling the Amsterdam II criteria for Lynch syndrome. PLoS ONE 10: e0130018, 2015.

27 Kamiza AB, Hsieh LL, Tang R, Chien HT, Lai CH, Chiu LL, Lo TP, Hung KY, You JF, Wang WC, Hsiung CA and Yeh CC:TP53 polymorphisms and colorectal cancer risk in patients with Lynch syndrome in Taiwan: A retrospective cohort study. PLoS ONE 11: e0167354, 2016.

28 Antoniou AC, Goldgar DE, Andrieu N, Chang-Claude J, Brohet R, Rookus MA and Easton DF: A weighted cohort approach for analysing factors modifying disease risks in carriers of high-risk susceptibility genes. Genet Epidemiol 29: 1-11, 2005.

29 Williams RL: A note on robust variance estimation for clustercorrelated data. Biometrics 56: 645-646, 2000.

30 Lurje G, Nagashima F, Zhang W, Yang D, Chang HM, Gordon MA, El-Khoueiry A, Husain H, Wilson PM, Ladner RD, Mauro DJ, Langer C, Rowinsky EK and Lenz HJ: Polymorphisms in cyclooxygenase- 2 and epidermal growth factor receptor are associated with progression-free survival independent of K-ras in metastatic colorectal cancer patients treated with single-agent cetuximab. Clin Cancer Res 14: 7884-7895, 2008.

31 Martinelli M, Ugolini G, Scapoli L, Rivetti S, Lauriola M, Mattei G, Rosati G, Montroni I, Manaresi A, Zattoni D, Taffurelli M and Solmi R: The EGFR R521K polymorphism influences the risk to develop colorectal cancer. Cancer Biomark 8: 61-65, 2010. 
32 Lai CY, Sung FC, Hsieh LL, Tang R, Chiou HY, Wu FY and Yeh $\mathrm{CC}$ : Associations between genetic polymorphisms of epidermal growth factor receptor and survival of colorectal cancer patients treated with 5-fluorouracil-based chemotherapy. Ann Surg Oncol 20: S599-606, 2013.

33 Moriai T, Kobrin MS, Hope C, Speck L and Korc M: A variant epidermal growth factor receptor exhibits altered type alpha transforming growth factor binding and transmembrane signaling. Proc Natl Acad Sci 91: 10217-10221,1994.

34 Kuang C, Xiao Y, Liu X, Stringfield TM, Zhang S, Wang Z and Chen Y: In vivo disruption of TGF- $\beta$ signaling by Smad7 leads to premalignant ductal lesions in the pancreas. Proc Natl Acad Sci 103: 1858-1863, 2006.

35 Broderick P, Carvajal-Carmona L, Pittman AM, Webb E, Howarth K, Rowan A, Lubbe S, Spain S, Sullivan K, Fielding S , Jaeger E, Vijayakrishnan J, Kemp Z, Gorman M, Chandler I, Papaemmanuil E, Penegar S, Wood W, Sellick G, Qureshi M, Teixeira A, Domingo E, Barclay E, Martin L, Sieber O, Consortium C, Kerr D, Gray R, Peto J, Cazier JB, Tomlinson I and Houlston RS: A genome-wide association study shows that common alleles of SMAD7 influence colorectal cancer risk. Nat Genet 39: 1315-1317, 2007.

$36 \mathrm{Hu} \mathrm{Y,} \mathrm{Sun} \mathrm{Z,} \mathrm{Zhang} \mathrm{A} \mathrm{and} \mathrm{Zhang} \mathrm{J:} \mathrm{SMAD7} \mathrm{rs12953717}$ polymorphism contributes to increased risk of colorectal cancer. Tumour Biol 35: 695-699, 2014.

37 Jiang X, Castelao JE, Vandenberg D, Carracedo A, Redondo CM, Conti DV, Paredes Cotoré JP, Potter JD, Newcomb PA, Passarelli MN, Jenkins MA, Hopper JL, Gallinger S, Le Marchand L, Martínez ME, Ahnen DJ, Baron JA, Lindor NM, Haile RW and Gago-Dominguez M: Genetic variations in SMAD7 are associated with colorectal cancer risk in the colon cancer family registry. PLoS ONE 8: e60464, 2013.
38 Slattery ML, Herrick J, Curtin K, Samowitz W, Wolff RK, Caan BJ, Duggan D, Potter JD and Peters U: Increased risk of colon cancer associated with a genetic polymorphism of SMAD7. Cancer Res 70: 1479-1485, 2010.

39 Wijnen JT, Brohet RM, van Eijk R, Jagmohan-Changur S, Middeldorp A, Tops CM, van Puijenbroek M, Ausems MGEM, Gómez García E, Hes FJ, Hoogerbrugge N, Menko FH, van Os TAM, Sijmons RH, Verhoef S, Wagner A, Nagengast FM, Kleibeuker JH, Devilee P, Morreau H, Goldgar D, Tomlinson IP, Houlston RS, van Wezel T and Vasen HFA : Chromosome $8 \mathrm{q} 23.3$ and 11q23.1 variants modify colorectal cancer risk in Lynch syndrome. Gastroenterology 136: 131-137, 2009.

40 Yan X, Liao H, Cheng M, Shi X, Lin X, Feng XH and Chen YG: Smad7 Protein interacts with receptor-regulated smads to inhibit transforming growth factor- $\beta /$ smad signaling. J Biol Chem 291 : 382-392, 2016

41 Huang F, Li L, Shen C, Wang H, Chen J, Chen W and Chen X: Association between TGFBR2 gene polymorphisms and congenital heart defects in Han Chinese population. Nutr Hosp 31: 710-715, 2015.

42 Li XT, Shen CQ, Zhang R, Shi JK, Li ZH, Liu HY, Sun B, Wang $\mathrm{K}$ and Yan LR: Association of TGFBR2 rs6785358 polymorphism with increased risk of congenital ventricular septal defect in a Chinese population. Pediatr Cardiol 36: 1476-1482, 2015.

Received August 15, 2018

Revised September 18, 2018 Accepted September 19, 2018 